\title{
Longitudinal relationships between cardiovascular events, risk factors, and time-dependent sleep duration
}

\author{
Daiki Kobayashi ${ }^{1,2}$, Nagato Kuriyama ${ }^{3}$, Yasuhiro Osugi, ${ }^{4,5}$, \\ Hiroko Arioka ${ }^{1}$, Osamu Takahashi ${ }^{1,2}$ \\ ${ }^{1}$ Department of Medicine, Division of General Internal Medicine, \\ St. Luke's International Hospital, Tokyo, Japan \\ ${ }^{2}$ Center for Clinical Epidemiology, St. Luke's Life Science Institute, Tokyo, Japan \\ ${ }^{3}$ Department of Epidemiology for Community Health and Medicine, \\ Kyoto Prefectural University of Medicine, Kyoto, Japan \\ ${ }^{4}$ Toyota Regional Medical Center, Toyota, Japan \\ ${ }^{5}$ Fujita Health University, Toyoake, Japan
}

\begin{abstract}
Background: Although many studies have evaluated the relationships between sleep duration and cardiovascular (CV) events/risk factors, longitudinal associations with time-dependent sleep duration have not been adequately assessed.

Methods: A retrospective, longitudinal study was conducted involving individuals aged 20 years or older that received annual health check-ups at St. Luke's International Hospital from 2005 to 2010. Data collection included self-reported demographic, clinical and health habit information (including sleep duration; <6, 6-7, 7-8, $\geq 8$ h), baseline examinations, and laboratory measures for each year. We conducted mixed effects analyses to examine the associations between non-fatal CV events, risk factors, and time-dependent sleep duration longitudinally.

Results: Of the total of 31,830 participants enrolled, $70.1 \%$ of participants changed their sleep duration, and 365 participants experienced CV events during follow-up periods. Compared to those reporting $7-8 \mathrm{~h}$ of sleep, those reporting less than $6 \mathrm{~h}$ of sleep were significantly more likely to experience non-fatal $C V$ events (odds ratio [OR] 1.78; 95\% confidence interval [CI] 1.03-3.07; $p=0.04$ ), but other groups were not (OR 1.12; 95\% CI 0.70-1.77; $p=0.64$ for $6-7$ h and OR 1.22; 95\% CI 0.68-2.23; $p=0.50$ for $\geq 8 \mathrm{~h}$ ). The shortest sleep duration was associated with a higher likelihood of obesity/overweight status (OR 1.49; 95\% CI 1.32-1.69; $p<0.01$ ).

Conclusions: Individuals reporting less than $6 \mathrm{~h}$ of sleep were significantly more likely to have nonfatal CV events than those reporting 7-8 h of sleep. For the risk factors, short sleep duration was associated with obesity/overweight status. (Cardiol J 2018; 25, 2: 229-235)
\end{abstract}

Key words: sleep duration, longitudinal study, cardiovascular events, cardiovascular risk factors

Address for correspondence: Daiki Kobayashi, MD, MPH, MBA, Division of General Internal Medicine, Department of Medicine, St. Luke's International Hospital, Tokyo, Japan, tel/fax: +81-3-3541-5151, e-mail: daikoba@luke.ac.jp 


\section{Introduction}

Since the 1990's, many studies have noted that people with short sleep durations have worse health outcomes [1-3]. Short sleep duration may be associated with mortality, cardiovascular (CV) events, and CV risk factors. Most of these studies indicate that getting less than $6 \mathrm{~h}$ of sleep per day is associated with higher incidences of these risk factors and events $[2.4,5]$. Some studies mention that longer sleep duration (more than 9 or $10 \mathrm{~h}$ ) is also associated with higher incidences of these risk factors and events compared to adequate sleep duration $(7-8 \mathrm{~h})[6,7]$. Other studies had CV risk factors as the outcome measurements. The risk factors included hypertension [8,9], diabetes (impaired glucose tolerance) [10-12], dyslipidemia (high cholesterol level) [13-15], metabolic syndrome [16, 17] and obesity (weight gain) [18-20]. Although the majority of prior studies suggested negative effects of short sleep duration on health outcomes, some could not demonstrate these effects [21-23]. As a result, the associations are still controversial.

Among these previous studies, most evaluated the relationships only by baseline sleep duration. For instance, one study evaluated the development of coronary heart disease with a one-time baseline sleep duration 10 years ago [3]. Very few studies have evaluated the relationships by time trends of sleep duration through longitudinal studies. In the limited number of longitudinal studies, sleep duration was repeatedly measured very few times. In addition, a previous study suggested that sleep duration variability is an independent risk factor for CV risk factors [24]. This means that most people may change their sleep habits. Therefore, longitudinal studies with time-dependent sleep duration variables are needed to evaluate the effect of sleep duration on health more precisely.

The goal of this study is to investigate the relationships between time-dependent sleep duration and $\mathrm{CV}$ events and risk factors using large-scale longitudinal data.

\section{Methods}

\section{Study participants}

This is a retrospective, longitudinal study with all subjects participating in an annual voluntary health check-up program at the Center for Preventive Medicine at St. Luke's International Hospital in Tokyo, Japan from 2005 to 2010. All participants completed a questionnaire about de- mographic information and health habits, including sleep duration and medical history, and underwent physical examinations and laboratory tests in an annual health check-up. The same information was obtained for each year during the study period. All participants included were 20 years or older in 2005. Individuals excluded had past medical histories of CV disease, including stroke. All data were extracted from electronic medical records.

\section{Ethical approval and informed consent}

The St. Luke's International Hospital Ethics Committee institutional review board approved this study.

Because this study was a retrospective cohort study, opt-out methodology wasapplied. Those that chose not to participate in the research were excluded.

\section{Measurement}

Sleep duration. Sleep duration was measured by participant response to a question about sleep duration. Participants filled the blank "Sleep duration: _ _ hours". Participants were classified into four groups based on their answers: less than $6 \mathrm{~h}$, $6 \mathrm{~h}$ to less than $7 \mathrm{~h}, 7 \mathrm{~h}$ to less than $8 \mathrm{~h}$, or more than $8 \mathrm{~h}$ [18]. The category of $7 \mathrm{~h}$ to less than $8 \mathrm{~h}$ was considered as normal sleep duration and defined this group as the reference group in this study. Based on previous studies, a mean daily sleep time of less than $6 \mathrm{~h}$ was considered as a short sleep duration [25, 26].

Outcomes. Primary outcomes included nonfatal CV events and the development of CV risk factors during follow-ups. Non-fatal CV events were determined based on a self-reported questionnaire at each health check-up. The development of $\mathrm{CV}$ risk factors was defined as self-reported and newly diagnosed hypertension, diabetes, dyslipidemia, and overweight/obesity status or abnormal related measurements on each factor. Participants with hypertension were defined as those with a self-reported history of hypertension, a measured systolic blood pressure of $140 \mathrm{~mm} \mathrm{Hg}$ or greater, or a diastolic blood pressure of $90 \mathrm{~mm} \mathrm{Hg}$ or greater [27, 28]. In the same way, participants with diabetes mellitus were defined as those with a self-reported history of diabetes, a fasting blood sugar of $126 \mathrm{mg} / \mathrm{dL}$ or greater, or a hemoglobin A1c (HbA1c) of $6.5 \%$ or greater $[29,30]$. Participants with dyslipidemia were defined as those with a self-reported history, a lowdensity lipoprotein cholesterol level of $140 \mathrm{mg} / \mathrm{dL}$ or greater, a high-density lipoprotein cholesterol 
level of $40 \mathrm{mg} / \mathrm{dL}$ or less, or a triglyceride level of $150 \mathrm{mg} / \mathrm{dL}$ or greater based on the criteria of the Japan Atherosclerosis Society [31]. Overweight/ /obesity status was defined as a measured body mass index of $25 \mathrm{~kg} / \mathrm{m}^{2}$ or higher based on the World Health Organization criteria for Asians [32].

Covariates. Participants were asked about the types and amount of alcohol they consumed in a week. Calculated average daily alcohol consumption was based on the questionnaire and participants were classified into two categories, excessive alcohol consumption vs. non-excessive alcohol consumption. Excessive alcohol consumption was defined as drinking more than $28 \mathrm{~g} /$ day (2 drinks) for males and $14 \mathrm{~g} /$ day ( 1 drink) for females based on criteria from the Centers for Disease Control and Prevention [33].

Participants were also asked about cigarette smoking and average number of packs of cigarettes smoked daily. They were classified as current smoker, former smoker, or never a smoker.

They were also asked about exercise habits in the form of how many times they exercised per week. Participants were classified as those who exercised regularly (at least 3 times a week) or those who exercised less than 3 times per week. Participants were asked about their occupations as well. Participant occupations were divided into three categories: unemployed, non-physical job and physical job, based on the answers from the selfreported questionnaire. Marital status was divided into two categories: married and unmarried.

\section{Statistical methods}

Cross-sectional analyses were conducted on participant characteristics at baseline in 2005 . $\chi^{2}$ tests were applied to categorical variables, and analysis of variance (ANOVA) was used for continuous variables. Then, longitudinal analyses were performed with the data from 2006 to 2010 to investigate the longitudinal association between sleep duration and CV events and risk factors. Adjusted odds ratios (OR) for binominal outcomes of future non-fatal $\mathrm{CV}$ events and risk factors were obtained with the model of the binominal family with the logit link function. To account for repeated observations within participants and random effects of observations, a mixed effects model were applied with an unstructured working correlation. To account for changes in sleep duration over time, sleep durations were designated differently as time-dependent variables in longitudinal analyses.

All analyses were performed in 2012 using SPSS 19.0J statistical software (IBM Japan, Tokyo,
Japan) and STATA 14 (STATA Corp., College Station, TX, USA).

\section{Results}

In $2005,40,035$ participants received annual health check-ups. Among them, 796 were excluded due to past CV events. Participant characteristics at baseline are shown in Table 1 . In terms of participant demographic information, those that reported less than $6 \mathrm{~h}$ of sleep at baseline tended to be younger and have more physical jobs but typically smoked cigarettes frequently, had infrequent exercise habits and were unmarried. In terms of clinical factors, those reporting shorter sleep duration tended to have less comorbidities and clinical measurements (95\% confidence interval [CI] 0.66-0.85).

In longitudinal analyses, $31,830(81.1 \%)$ participants attended health check-ups at least one time during the study periods. Throughout the follow-up periods, $70.1 \%$ of individuals changed their sleep duration category from baseline. However, the proportion of each sleep duration category were stable over the study period (Fig. 1). Three hundred sixty-five $(1.1 \%)$ participants developed $\mathrm{CV}$ events. Longitudinal analyses revealed that those reporting less than $6 \mathrm{~h}$ sleep duration had a significantly higher OR of 1.78 (95\% CI 1.03-3.07) for non-fatal CV events compared to those reporting $7-8 \mathrm{~h}$ sleep duration. In terms of clinical factors, those with short sleep duration (less than $6 \mathrm{~h}$ ) were significantly overweight/obese (OR $1.49,95 \%$ CI 1.32-1.69) but had lower rates of development for hypertension (OR $0.75,95 \%$ CI $0.66-0.85$ ) and dyslipidemia (OR 0.90, 95\% CI 0.81-0.98) (Table 2). Table 3 shows the longitudinal relationships between clinical measurements and time-dependent sleep duration. These results were consistent with those for clinical factors, except for HbAlc ( $\beta$ coefficient: $0.01,95 \%$ CI $0.01-0.02$ ). In terms of longer sleep duration than $8 \mathrm{~h}$, participants had no significant findings for all outcomes.

\section{Discussion}

In our longitudinal study, time-dependent short sleep duration was associated with the development of $\mathrm{CV}$ events and obesity/overweight status, which is consistent with the majority of previous cross-sectional and cohort studies. In contrast, time-dependent short sleep duration had favorable associations with diabetes and dyslipidemia, which is inconsistent with previous studies. 
Table 1. Participant characteristics by sleep duration at baseline $(n=39,239)$.

\begin{tabular}{|c|c|c|c|c|c|}
\hline & \multicolumn{5}{|c|}{ Sleep category } \\
\hline & $\begin{array}{c}<6 h \\
(24.9 \%)\end{array}$ & $\begin{array}{c}6-7 \mathrm{~h} \\
(40.1 \%)\end{array}$ & $\begin{array}{c}7-8 \mathrm{~h} \\
(25.8 \%)\end{array}$ & $\begin{array}{c}>8 h \\
(8.4 \%)\end{array}$ & $\mathbf{P}$ \\
\hline \multicolumn{6}{|l|}{ Demographics: } \\
\hline Age [year] & $43.7 \pm 10.8$ & $46.9 \pm 11.5)$ & $50.2 \pm 12.6)$ & $53.5 \pm 14.3)$ & $<0.01$ \\
\hline Male & 51.1 & 49.1 & 50.1 & 51.2 & $<0.01$ \\
\hline \multicolumn{6}{|l|}{ Social habit and status: } \\
\hline Excessive alcohol use* & $17.2 \%$ & $16.4 \%$ & $16.6 \%$ & $19.8 \%$ & 0.04 \\
\hline Current smoker & $22.2 \%$ & $18.9 \%$ & $16.9 \%$ & $18.2 \%$ & $<0.01$ \\
\hline Exercise $\geq 3$ times a week & $19.5 \%$ & $22.9 \%$ & $28.2 \%$ & $32.4 \%$ & $<0.01$ \\
\hline Physical job & $16.7 \%$ & $13.7 \%$ & $12.6 \%$ & $13.9 \%$ & $<0.01$ \\
\hline Married & $62.7 \%$ & $70.4 \%$ & $76.4 \%$ & $78.9 \%$ & $<0.01$ \\
\hline \multicolumn{6}{|l|}{ Clinical factors: } \\
\hline Hypertension $^{\dagger}$ & $12.6 \%$ & $14.8 \%$ & $19.6 \%$ & $24.4 \%$ & $<0.01$ \\
\hline Diabetes $^{\ddagger}$ & $1.3 \%$ & $1.6 \%$ & $1.7 \%$ & $2.6 \%$ & 0.01 \\
\hline Dyslipidemia $^{\S}$ & $2.9 \%$ & $3.5 \%$ & $4.6 \%$ & $6 \%$ & $<0.01$ \\
\hline \multicolumn{6}{|l|}{ Clinical measurements: } \\
\hline Body mass index & $22.6 \pm 3.5$ & $22.4 \pm 3.3$ & $22.3 \pm 3.1$ & $22.2 \pm 3.2$ & $<0.01$ \\
\hline Systolic blood pressure & $115.9 \pm 16.6$ & $116.8 \pm 17.2$ & $119.1 \pm 18.1$ & $121.3 \pm 19.0$ & $<0.01$ \\
\hline Diastolic blood pressure & $72.1 \pm 10.9$ & $72.7 \pm 11.2$ & $74.0 \pm 11.4$ & $75.0 \pm 11.6$ & $<0.01$ \\
\hline Fasting blood sugar & $99.0 \pm 15.7$ & $99.3 \pm 15.6$ & $100.0 \pm 15.7$ & $101.0 \pm 17.8$ & $<0.01$ \\
\hline Hemoglobin A1c & $5.6 \pm 0.6$ & $5.1 \pm 0.6$ & $5.1 \pm 0.6$ & $5.2 \pm 0.6$ & $<0.01$ \\
\hline Total cholesterol & $198.9 \pm 34.3$ & $202.2 \pm 34.6$ & $204.8 \pm 33.9$ & $207.4 \pm 35.2$ & 0.1 \\
\hline LDL cholesterol & $114.2 \pm 30.3$ & $116.2 \pm 30.3$ & $117.7 \pm 29.7$ & $119.2 \pm 30.8$ & 0.11 \\
\hline HDL cholesterol & $62.2 \pm 15.9$ & $62.4 \pm 15.8$ & $62.2 \pm 15.8$ & $61.8 \pm 15.8$ & 0.95 \\
\hline Triglycerides & $98.9 \pm 82.0$ & $101.3 \pm 86.1$ & $102.6 \pm 75.6$ & $108.7 \pm 88.7$ & $<0.01$ \\
\hline
\end{tabular}

HDL — high-density lipoprotein; LDL — low-density lipoprotein

*Excessive alcohol use indicates consuming more than $28 \mathrm{~g}$ of alcohol per day for males and $14 \mathrm{~g}$ per day for females

tHypertension indicates those with a history of hypertension or abnormality at baseline

¥Diabetes mellitus indicates those with a history of diabetes mellitus or abnormality in 2005

§Dyslipidemia indicates those with a history of dyslipidemia or abnormality in 2005

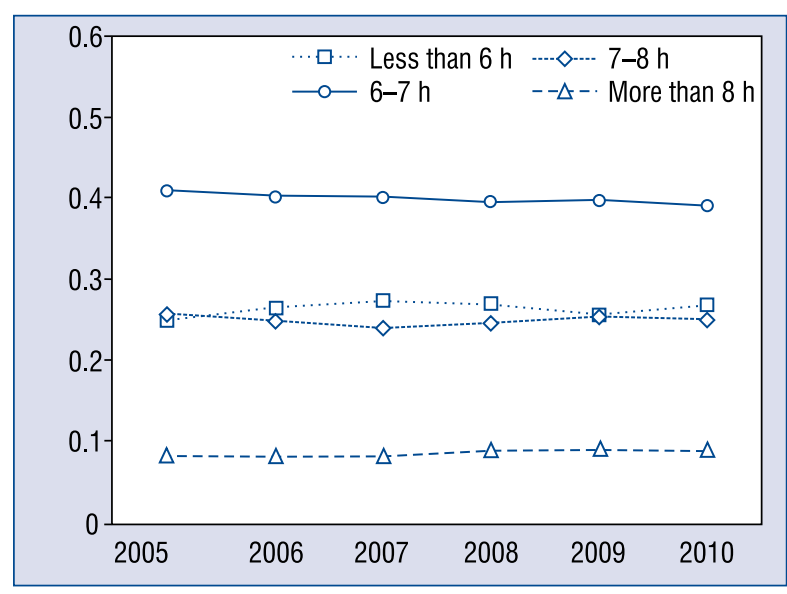

Figure 1. Trends of the sleep duration category over 5 years.
The associations between sleep duration and CV events or risk factors are still controversial, especially for specific populations such as the elderly [34] or obese people [35]. Although a conclusion was not reached, adequate sleep duration would be clinically favorable compared to extremely short or long sleep duration.

In terms of $\mathrm{CV}$ events, obesity/overweight status and diabetes findings in our study were consistent with the majority of previous studies, even accounting for time-dependent sleep duration. Many previous studies discuss the mechanisms for the association between short sleep duration, CV events, and obesity. These may manifest through biochemical causes [36], social-behavioral causes [37], and/or CV risk-associated diseases. One 
Table 2. Longitudinal association between time-dependent sleep duration and cardiovascular events/ /risk factors.

\begin{tabular}{|c|c|c|c|c|c|}
\hline & \multicolumn{5}{|c|}{ Adjusted odds ratios* (95\% confidence interval) } \\
\hline & $\begin{array}{c}\text { Cardiovascular } \\
\text { event }\end{array}$ & Hypertension $^{\dagger}$ & $\begin{array}{l}\text { Diabetes } \\
\text { mellitus }^{\ddagger}\end{array}$ & Dyslipidemia $^{\S}$ & $\begin{array}{l}\text { Overweight/ } \\
\text { /obesity status }\end{array}$ \\
\hline Less than $6 \mathrm{~h}$ & $1.78(1.03-3.07)$ & $0.75(0.66-0.85)$ & $1.18(0.95-1.46)$ & $0.90(0.81-0.98)$ & $1.49(1.32-1.69)$ \\
\hline $6-7 \mathrm{~h}$ & $1.12(0.70-1.77)$ & $0.87(0.79-0.97)$ & $1.11(0.93-1.32)$ & $0.95(0.87-1.03)$ & $1.19(1.07-1.32)$ \\
\hline $7-8 \mathrm{~h}$ & & & Reference & & \\
\hline More than $8 \mathrm{~h}$ & $1.22(0.68-2.23)$ & $1.06(0.92-1.24)$ & $1.10(0.86-1.40)$ & $0.96(0.85-1.09)$ & $0.90(0.76-1.07)$ \\
\hline
\end{tabular}

*Adjusted odds ratios: Models were adjusted for age, gender, occupation, health habits, marital status, calorie intake and time variables. Sleep duration was treated as the time-dependent variable. The numbers in bold indicate statistical significance with a $p$-value less than 0.05 tHypertension indicates those with a history of hypertension or abnormality at follow-ups

¥Diabetes mellitus indicates those with a history of diabetes mellitus or abnormality at follow-ups

$\S$ Dyslipidemia indicates those with a history of dyslipidemia or abnormality at follow-ups

**Overweight/obesity status indicates a body mass index higher than $25 \mathrm{~kg} / \mathrm{m}^{2}$ based on World Health Organization criteria for Asians at follow-ups

Table 3. Longitudinal association between time-dependent sleep duration and cardiovascular-related factors.

\begin{tabular}{|c|c|c|c|c|c|c|c|c|}
\hline & \multicolumn{8}{|c|}{ Adjusted $\beta$-coefficients* (95\% confidence interval) } \\
\hline & SBP & DBP & FBS & HbA1c & TC & LDL-C & HDL-C & TG \\
\hline $\begin{array}{l}\text { Less than } \\
6 \mathrm{~h}\end{array}$ & $\begin{array}{c}-0.45 \\
(-0.72 \\
\text { to }-0.18)\end{array}$ & $\begin{array}{c}-0.29 \\
(-0.46 \\
\text { to }-0.12)\end{array}$ & $\begin{array}{c}0.23 \\
(-0.02 \\
\text { to } 0.47)\end{array}$ & $\begin{array}{c}0.01 \\
(0.01 \\
\text { to } 0.02)\end{array}$ & $\begin{array}{c}-0.18 \\
(-0.74 \\
\text { to } 0.38)\end{array}$ & $\begin{array}{c}-0.22 \\
(-0.70 \\
\text { to } 0.26)\end{array}$ & $\begin{array}{c}\mathbf{0 . 6 6} \\
(0.46 \\
\text { to } 0.87)\end{array}$ & $\begin{array}{c}-2.42 \\
(-3.79 \\
\text { to }-1.06)\end{array}$ \\
\hline $6-7 \mathrm{~h}$ & $\begin{array}{c}-0.31 \\
(-0.53 \\
\text { to }-0.09)\end{array}$ & $\begin{array}{c}-0.09 \\
(-0.23 \\
\text { to } 0.05)\end{array}$ & $\begin{array}{c}0.05 \\
(-0.14 \\
\text { to } 0.25)\end{array}$ & $\begin{array}{c}0.01 \\
(0.01 \\
\text { to } 0.01)\end{array}$ & $\begin{array}{c}0.15 \\
(-0.30 \\
\text { to } 0.60)\end{array}$ & $\begin{array}{c}0.03 \\
(-0.36 \\
\text { to } 0.41)\end{array}$ & $\begin{array}{c}\mathbf{0 . 3 6} \\
(0.19 \\
\text { to } 0.52)\end{array}$ & $\begin{array}{r}-0.83 \\
(-1.95 \\
\text { to } 0.29)\end{array}$ \\
\hline $7-8 \mathrm{~h}$ & \multicolumn{8}{|c|}{ Reference } \\
\hline $\begin{array}{l}\text { More than } \\
8 \mathrm{~h}\end{array}$ & $\begin{array}{c}0.21 \\
(-0.13 \\
\text { to } 0.57)\end{array}$ & $\begin{array}{c}0.02 \\
(-0.20 \\
\text { to } 0.23)\end{array}$ & $\begin{array}{c}0.03 \\
(-0.28 \\
\text { to } 0.33)\end{array}$ & $\begin{array}{c}0.01 \\
(-0.01 \\
\text { to } 0.01)\end{array}$ & $\begin{array}{c}0.30 \\
(-0.40 \\
\text { to } 1.01)\end{array}$ & $\begin{array}{c}0.09 \\
(-0.52 \\
\text { to } 0.69)\end{array}$ & $\begin{array}{c}-0.08 \\
(-0.34 \\
\text { to } 0.17)\end{array}$ & $\begin{array}{c}1.62 \\
(-0.13 \\
\text { to } 3.37)\end{array}$ \\
\hline
\end{tabular}

*Adjusted $\beta$-coefficients: Models were adjusted for age, gender, occupation, health habits, marital status, calorie intake, treatment status outcomes and time variables. Sleep duration was treated as a time-dependent variable; The numbers in bold indicate statistical significance with a p-value less than 0.05

DBP - diastolic blood pressure; FBS - fasting blood sugar; HbA1c - hemoglobin A1c; HDL-C - high-density lipoprotein cholesterol; LDL-C — low-density lipoprotein cholesterol; SBP — systolic blood pressure; TG — triglycerides; TC — total cholesterol

previous study discussed the possible mechanisms for developing diabetes in association with short sleep duration [38]. According to the study, short sleep duration stimulates adipocytes and increases circulating adipokine levels. Another study suggested that short sleep duration may decrease insulin sensitivity [39]. As a result, short sleepers are susceptible to the development of diabetes. Therefore, the present findings that sleep duration less than $6 \mathrm{~h}$ had negative effects on health outcomes were supported.

The reasons why some findings, such as the results on hypertension and dyslipidemia, contradicted previous studies are unclear. The main difference between our study and other previous studies is that changes in sleep duration wereaccounted for over time within individuals. As mentioned above, approximately $70 \%$ of participants changed their sleep duration from baseline during the study period. This adaptation and other potential confounders may explain the differences in results between this study and other predominant studies. For instance, individuals with obstructive sleep apnea syndrome or insomnia described as having short sleep duration may have been treated for these disorders. As a result, hypertension, which is major complication of these disorders, may be resolved. In addition, there are several possible factors that may be prompted by dynamic social circumstances and could be associated with 
the results. Social stress, sleep disturbance from night-shift working or lifestyle changes, reduced physical activity related to transportation or hormonal disorders are all examples of factors that may be related to the results. Furthermore, the fact that the category of those sleeping less than $6 \mathrm{~h}$ included younger participants may explain the unexpected results.

\section{Limitations of the study}

There are some limitations in this study. First, some of the participants were not followed-up. Although the follow-up rate was more than $80 \%$, those that were not followed may bias the results. However, considering the retrospective nature of the study, it is believed that a greater than $80 \%$ follow-up rate is still acceptable and therefore the bias is limited. In addition, they may be more interested in their health than the general population, because this is a completely voluntary health check. This may induce selection bias. Second, our data did not contain certain confounders such as quality of sleep, history of insomnia or sleep apnea syndrome. In addition, some information was lacking which related to $\mathrm{CV}$ events/risk factors, such as pathology and treatment status. These confounders may have influenced the results. Self-reported sleep duration and clinical outcomes may induce recall bias. Finally, quality of sleep may also be important for precise evaluations of the discussed associations. Further studies, which are prospective, have objective measurement for sleep duration, and have information about quality of sleep are needed to evaluate the longitudinal associations.

\section{Conclusions}

In this study, significant associations between short sleep duration and CV events and obesity/ /overweight status were observed, even in consideration of sleep duration as a time-dependent variable. Relationships between sleep duration and other risk factors, including hypertension and dyslipidemia, are still controversial.

\section{Conflict of interest: None declared}

\section{References}

1. Qureshi AI, Giles WH, Croft JB, et al. Habitual sleep patterns and risk for stroke and coronary heart disease: a 10-year followup from NHANES I. Neurology. 1997; 48(4): 904-911, indexed in Pubmed: 9109875.

2. Heslop P, Smith GD, Metcalfe C, et al. Sleep duration and mortality: The effect of short or long sleep duration on cardiovascular and all-cause mortality in working men and women. Sleep Med. 2002; 3(4): 305-314, indexed in Pubmed: 14592192.

3. Ayas NT, White DP, Manson JE, et al. A prospective study of sleep duration and coronary heart disease in women. Arch Intern Med. 2003; 163(2): 205-209, indexed in Pubmed: 12546611.

4. Meisinger C, Heier M, Löwel H, et al. Sleep duration and sleep complaints and risk of myocardial infarction in middle-aged men and women from the general population: the MONICA/ KORA augsburg cohort study. Sleep. 2007; 30(9): 1121-1127, doi: 10.1093/sleep/30.9.1121.

5. St-Onge MP, Grandner MA, Brown D, et al. Sleep duration and quality: impact on lifestyle behaviors and cardiometabolic health: a scientific statement from the American Heart Association. Circulation. 2016; 134(18): e367-e386, doi: 10.1161/ CIR.0000000000000444, indexed in Pubmed: 27647451.

6. Shankar A, Koh WP, Yuan JM, et al. Sleep duration and coronary heart disease mortality among Chinese adults in Singapore: a population-based cohort study. Am J Epidemiol. 2008; 168(12): 1367-1373, doi: 10.1093/aje/kwn281, indexed in Pubmed: 18952563.

7. Kakizaki M, Kuriyama S, Nakaya N, et al. Long sleep duration and cause-specific mortality according to physical function and self-rated health: the Ohsaki Cohort Study. J Sleep Res. 2013; 22(2): 209-216, doi: 10.1111/j.1365-2869.2012.01053.x, indexed in Pubmed: 23005259.

8. Knutson KL, Van Cauter E, Rathouz PJ, et al. Association between sleep and blood pressure in midlife: the CARDIA sleep study. Arch Intern Med. 2009; 169(11): 1055-1061, doi: 10.1001/ archinternmed.2009.119, indexed in Pubmed: 19506175.

9. Stranges S, Dorn JM, Cappuccio FP, et al. A population-based study of reduced sleep duration and hypertension: the strongest association may be in premenopausal women. J Hypertens. 2010; 28(5): 896-902, doi: 10.1097/HJH.0b013e328335d076, indexed in Pubmed: 20040890.

10. Rafalson L, Donahue RP, Stranges S, et al. Short sleep duration is associated with the development of impaired fasting glucose: the Western New York Health Study. Ann Epidemiol. 2010; 20(12): 883-889, doi: 10.1016/j.annepidem.2010.05.002, indexed in Pubmed: 20620078.

11. Chao CY, Wu JS, Yang YC, et al. Sleep duration is a potential risk factor for newly diagnosed type 2 diabetes mellitus. Metabolism. 2011; 60(6): 799-804, doi: 10.1016/j.metabol.2010.07.031, indexed in Pubmed: 20846701.

12. Rutters F, Besson H, Walker M, et al. The association between sleep duration, insulin sensitivity, and $\beta$-Cell function: the EGIRRISC study. J Clin Endocrinol Metab. 2016; 101(9): 3272-3280, doi: 10.1210/jc.2016-1045, indexed in Pubmed: 27355399.

13. Taveras EM, Rifas-Shiman SL, Rich-Edwards JW, et al. Association of maternal short sleep duration with adiposity and cardiometabolic status at 3 years postpartum. Obesity (Silver Spring). 2011; 19(1): 171-178, doi: 10.1038/oby.2010.117, indexed in Pubmed: 20489690.

14. Moraes W, Poyares D, Zalcman I, et al. Association between body mass index and sleep duration assessed by objective methods in a representative sample of the adult population. Sleep Med. 2013; 14(4): 312-318, doi: 10.1016/j.sleep.2012.11.010, indexed in Pubmed: 23391395.

15. Toyama Y, Chin K, Chihara Y, et al. Association between sleep apnea, sleep duration, and serum lipid profile in an urban, male, working population in Japan. Chest. 2013; 143(3): 720-728, doi: 10.1378/chest.12-0338, indexed in Pubmed: 23081691. 
16. Najafian J, Toghianifar N, Mohammadifard N, et al. Association between sleep duration and metabolic syndrome in a populationbased study: Isfahan Healthy Heart Program. J Res Med Sci. 2011; 16(6): 801-806, indexed in Pubmed: 22091310.

17. Kobayashi D, Takahashi O, Deshpande GA, et al. Relation between metabolic syndrome and sleep duration in Japan: a large scale cross-sectional study. Intern Med. 2011; 50(2): 103-107, indexed in Pubmed: 21245632.

18. Kobayashi D, Takahashi O, Deshpande GA, et al. Association between weight gain, obesity, and sleep duration: a largescale 3-year cohort study. Sleep Breath. 2012; 16(3): 829-833, doi: 10.1007/s11325-011-0583-0, indexed in Pubmed: 21892668.

19. Dashti HS, Follis JL, Smith CE, et al. Habitual sleep duration is associated with BMI and macronutrient intake and may be modified by CLOCK genetic variants. Am J Clin Nutr. 2015; 101(1): 135143, doi: 10.3945/ajcn.114.095026, indexed in Pubmed: 25527757.

20. Calvin AD, Carter RE, Adachi T, et al. Effects of experimental sleep restriction on caloric intake and activity energy expenditure. Chest. 2013; 144(1): 79-86, doi: 10.1378/chest.12-2829, indexed in Pubmed: 23392199.

21. Cole HV, Owusu-Dabo E, Iwelunmor J, et al. Sleep duration is associated with increased risk for cardiovascular outcomes: a pilot study in a sample of community dwelling adults in Ghana. Sleep Med. 2017; 34: 118-125, doi: 10.1016/j.sleep.2017.03.008, indexed in Pubmed: 28522079.

22. Yan LX, Chen XR, Chen Bo, et al. Gender-specific association of sleep duration with body mass index, waist circumference, and body fat in chinese adults. Biomed Environ Sci. 2017; 30(3): 157-169, doi: 10.3967/bes2017.023, indexed in Pubmed: 28427485.

23. He Q, Sun H, Wu X, et al. Sleep duration and risk of stroke: a dose-response meta-analysis of prospective cohort studies. Sleep Med. 2017; 32: 66-74, doi: 10.1016/j.sleep.2016.12.012, indexed in Pubmed: 28366344.

24. Kobayashi D, Takahashi O, Shimbo T, et al. High sleep duration variability is an independent risk factor for weight gain. Sleep Breath. 2013; 17(1): 167-172, doi: 10.1007/s11325-012-0665-7, indexed in Pubmed: 22354882.

25. Fernandez-Mendoza J, Vgontzas AN, Liao D, et al. Insomnia with objective short sleep duration and incident hypertension: the Penn State Cohort. Hypertension. 2012; 60: 929-35.

26. Lallukka T, Kaikkonen R, Härkänen T, et al. Sleep and sickness absence: a nationally representative register-based follow-up study. Sleep. 2014; 37(9): 1413-1425, doi: 10.5665/sleep.3986, indexed in Pubmed: 25142569.

27. Chobanian AV, Bakris GL, Black HR, et al. The Seventh Report of the Joint National Committee on Prevention, Detec- tion, Evaluation, and Treatment of High Blood Pressure: the JNC 7 report. JAMA. 2003; 289(19): 2560-2572, doi: 10.1001/ jama.289.19.2560, indexed in Pubmed: 12748199.

28. James PA, Oparil S, Carter BL, et al. 2014 evidence-based guideline for the management of high blood pressure in adults: report from the panel members appointed to the Eighth Joint National Committee (JNC 8). JAMA. 2014; 311(5): 507-520, doi: 10.1001/ jama.2013.284427, indexed in Pubmed: 24352797.

29. Diagnosis and classification of diabetes mellitus. Diabetes Care. 2010; 33(Suppl 1): S62-9.

30. International Expert Committee. International Expert Committee report on the role of the $\mathrm{A} 1 \mathrm{C}$ assay in the diagnosis of diabetes. Diabetes Care. 2009; 32(7): 1327-1334, doi: 10.2337/ dc09-9033, indexed in Pubmed: 19502545.

31. Guidelines for Prevention of Aherosclerotic Cardiovascular Diseases. Japan Atherosclerosis Society. 2007.

32. Appropriate body-mass index for Asian populations and its implications for policy and intervention strategies. Lancet. 2004; 363(9403): 157-163, doi:10.1016/s0140-6736(03) 15268-3.

33. Alcohol and Public Health. Centers for Disease Control and Prevention, 2013. http://www.cdc.gov/Alcohol/ (Accessed Feb 9, 2013).

34. Wu X, Sun Y, Niu K, et al. Association of self-reported sleep duration and hypertension: Results of a Chinese prospective cohort study. Clin Exp Hypertens. 2016; 38(6): 514-519, doi: 10.3109/1 0641963.2016.1163367, indexed in Pubmed: 27391917.

35. Song MY, Sung En, Jung SP, et al. The association between sleep duration and hypertension in non-obese premenopausal women in Korea. Korean J Fam Med. 2016; 37(2): 130-134, doi: 10.4082/ kjfm.2016.37.2.130, indexed in Pubmed: 27073613.

36. Weil BR, Mestek ML, Westby CM, et al. Short sleep duration is associated with enhanced endothelin-1 vasoconstrictor tone. Can J Physiol Pharmacol. 2010; 88(8): 777-781, doi: 10.1139/ Y10-046, indexed in Pubmed: 20725134.

37. Schmid SM, Hallschmid M, Jauch-Chara K, et al. Short-term sleep loss decreases physical activity under free-living conditions but does not increase food intake under time-deprived laboratory conditions in healthy men. Am J Clin Nutr. 2009; 90(6): 1476-1482, doi: 10.3945/ajcn.2009.27984, indexed in Pubmed: 19846546.

38. Hayes AL, Xu F, Babineau D, et al. Sleep duration and circulating adipokine levels. Sleep. 2011; 34(2): 147-152, indexed in Pubmed: 21286230.

39. Eckel RH, Depner CM, Perreault L, et al. Morning circadian misalignment during short sleep duration impacts insulin sensitivity. Curr Biol. 2015; 25(22): 3004-3010, doi: 10.1016/j. cub.2015.10.011, indexed in Pubmed: 26549253. 